\title{
Studying the Cultivation of Public Humanities and Social Science Literacy on the Horizon of Ecological Civilization"
}

\author{
Qing Cheng \\ Tianjin University of Technology and Education \\ Tianjin, 300222, China \\ e-mail: jjchengq@163.com
}

\begin{abstract}
Based on the analysis of ecological civilization under the horizon of the importance of cultivating the public quality of humanistic and social science, this paper discusses the construction of ecological civilization as a systematic project, and development of humanities and social science literacy, as a focal point of ecological civilization in cultivating public humanities and social science literacy, is the foundation of the systematic project. The goal of this cultivation should meet the requirements of the relevant education on ecological civilization. This paper proposes the scientific literacy of the public relations directly relating to the professional skills, and forming the public accomplishment, to which humanities and social science and educational level are positively related, and aims at and analyzes the strategies in developing public humanities and social science.
\end{abstract}

Keywords -ecological civilization; the public; humanities and social science literacy; cultivation

\section{INTRODUCTION}

Human society approaches the ecological civilization. Ecological civilization means the harmonious coexistence of human beings, between human and nature, between man and society, which is a virtuous cycle, and the whole development following the continued prosperity and ecological civilization. It refers to the harmonious development of human beings and nature, society, the objective law and the sum of material and spiritual achievements. It is a sustainable development of ecological ethics, namely, human should be in harmony with nature, and have the right to enjoy healthy and productive life, and it offers fair development and environment to meet the needs of the present generations. In the construction of the public moral accomplishments and ecological civilization, new requirements on humanities and social science literacy have been posed. Along with the economy developing rapidly, national strength has been markedly enhanced, science and technology have progressed, and people's material life has also made an unprecedented increase. Currently, the environmental protection and ecological construction tend to focus on the hardware investment, while ignoring the ecological moral accomplishment, public investment in humanities and social science literacy. In the process of ecological construction, people only pay attention to promoting project construction, but ignore the values, moral accomplishment, public correct guidance and the cultivation of humanities and social science literacy, ignoring the cultivation of ethical spirit and development of environmental protection. Consequently, the cultivation of public humanities and social science literacy does not get the attention they deserve. Therefore, we need to raise their awareness of humanities and social science, and to strengthen the education on modern humanities and social sciences. To improve the public's humanities and social science literacy has become a top priority in today's construction of ecological civilization.

\section{Cultivation of Public Humanities and Social} SCIENCE LITERACY IS THE OBJECTIVE REQUIREMENT OF Promoting ECOLOGICAL CiviLizATION AND TRANSFORMING THE ECONOMIC GROWTH PATTERNS

The experience and lessons in practice are useful capital and the foundation for people to survive and develop, for human beings cannot live without survival and development. Ecological civilization is a higher and better development, creating more favorable conditions. In socialist society, the realization of ecological civilization is a rite of passage.

Lacking effective high-tech input, the transformation of economic growth patterns is impossible without workers of high quality. Enhancing public social literacy is also the objective requirement of the transformation of economic growth mode, and the foundation for the comprehensive, coordinated and sustainable development of economy. In other words, it is the objective requirement of the construction of ecological civilization and the transformation of economic growth mode. Therefore, improving public accomplishment in humanities and social sciences has become one of the primary tasks in the construction of ecological civilization.

\section{The Public Humanities AND Social ScIENCE Literacy ARE DiReCTly RELATED to Vocational SKILlS}

Public humanities and social science literacy directly affects the public participation in the discussion of the construction of ecological civilization, science and technology policies and the building of decision-making ability. It also influences the public's impact on the public humanities and social sciences of lower level, on man and nature, man and society, Chinese harmonious coexistence, and on the development of science and technology, economy and culture, in the democratization and decision making process of the open government and leaders. Besides, it influences people's 
improving the quality of professional theoretical knowledge and practical skills including literacy, and thus, to enhance the public's humanities and social science literacy is imperative. First of all, let's discuss the public vocational skills and quality, define science, humanities, social science literacy and literacy, and explore their relationship.

\section{A. Quality and Accomplishment}

Quality is the essence of man and nature. As a spontaneous behavior, it is an individual that has been formed and keeps stable, generally not a kind of existing thought or external condition. Quality refers to the reflection of the development of a person's quality, level and the characteristics of personality. It is the relatively stable physical and mental development formed on the basis of one's congenital physical environment and under the influence of education acquired and recognition of individual activities and practice form. The specialization of profession requires professional quality with particularity greater. As self accomplishment and self-restraint, literacy influences the cognition, thinking and decision making of the person who is faced with ideal and background.

Quality shapes a person's personality, hobbies, philosophy and attitude, and what he/she accepts. Literacy means accepting all kinds of information to correct their ideas and behaviors while integrating into society.

\section{B. Humanities and social science literacy}

The literacy of humanities and social sciences, in comparison to that of natural science, also belongs to general scientific literacy. The so-called "humanities and social science literacy" refers to the spirit of the external performance including the knowledge, methods and recognition, understanding, mastery and application of the humanities and social science. This quality is mainly acquired through practices such as education, learning and practicing, and gradual improvement. Therefore, the public knowledge of humanities and social science literacy is not only a system, or a practical system, whose height is an important index of the development level of a country, but also can adapt to the modernization of the basic indicators in social life. Thus, everyone, as the tradition and culture of historical existence, is on the horizon. Every one of us represents a person's humanities and social science literacy, and should not only master the humanities and social science knowledge, but also use them effectively in solving practical problems, and acquire the necessary ability to adjust to and interact with the environment.

\section{The scientific qualities and professional skills of the public}

The quality of citizens signifies the fundamental condition for fitting themselves to the survival and developmental needs. It includes not only the scientific quality and humanities and social science quality, also includes the public's ideological and moral quality, physical quality and so on. It is the basic category, mainly including three integral parts: basically understanding scientific knowledge, the process and methods of scientific research, and the impact of science and technology on society and individuals. In addition, vocational skills, emphasizing the work in need of professional knowledge and skills, is a scientific literacy and the quality of further specialization.

The following model can be used to illustrate the relationship between Quality ( $Q$ for quality), literacy of science and technology, humanities and social science ( $\mathrm{K}$ for knowledge) and vocational skills (A for ability) :

$$
\mathrm{Q}-\mathrm{K}(\mathrm{Q})-\mathrm{A}
$$

The direct correlation between the three is shown more clearly.

$\mathrm{Q}$ is the foundation, while $\mathrm{K}$ is a function of $\mathrm{Q}$, showing that the development of scientific literacy should base on Q and explaining that as merely $\mathrm{Q}$ is not enough in practice, cultivating the $\mathrm{K}$ of the public, namely the deep layer of scientific literacy, is necessary. In the same way, it shows that in production activities, the public needs vocational skills most of all. Therefore, it is to develop (train) their scientific literacy and professional skills, and this project must be based on the public science literacy, due to the relationship illustrated as follow:

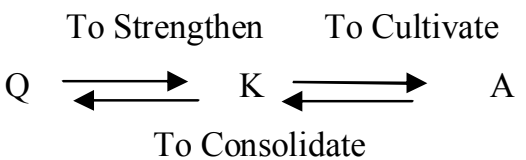

The front position of $\mathrm{Q}$ indicates the fundamental function of the quality, and a basic education at work. However, our focus is on the cultivation of "K - $\mathrm{A}$ " type talents, namely the cultivation of workers with knowledge and skills. "To solve practical problems, adjust the skilled workers' interaction with environment on the basis of technological literacy", which makes our work more targeted and poses higher standard and requirements of workers' literacy of science, humanities and social science, and vocational skills, also has more significance in actual application

\section{THE Formation OF SCIENTIFIC LitERACY}

The construction of ecological civilization is a systematic project. As the focus, the construction of ecological civilization includes the cultivation of public ecological ethics and humanities and social science literacy as its crucial element and the cultivation aims at meeting the requirements of education relating to ecological civilization. Citizens with humanities and social science literacy, acquires rich cultural knowledge, improves the capacity of applying knowledge in practice, and enhances the awareness of reform and opening up and sense of historical responsibility. Meanwhile, both gain good ecological moral accomplishment. This demands vigorously promoting the public to establish and satisfy new ideas. It also demands ecological civilization, new morality and values to serve as the foundation for understanding, supporting and participating in the construction of ecological civilization. The cultivation of humanities and social science literacy is a comprehensive education on ecological moral accomplishment, as ecological education is the main clue of moral behavior. The education on ecological moral accomplishment is the core of the cultivation of humanities and social science literacy. In order to develop, receiving 
education in classroom or at school is not enough, for transforming social practice into conscious behavior and a kind of self-discipline in real life if of greater importance.

\section{A. The public scientific literacy, humanities and social science literacy, and educational level}

According to relevant data, in different groups, the humanities and social science literacy influences the two enthusiasm of participating in society. In abiding by the norms of morality, and specifically to the public knowledge of humanities and social science, comparison of attitudes and deeds, the public criteria for classifying education, the public's cultural level of humanities and social science literacy is closely relative to their cultural degree, and is distinguished as the higher cultural level, namely:

$$
\mathrm{Y}=\mathrm{kX}+\mathrm{b} \quad(\mathrm{k}>0)
$$

Among them, the undergraduate education on the humanities and social sciences in universities improves the important position of humanities and social science in the public literacy level, increases the overall level of educatee's culture, and thus improves the integration of public accomplishment and the humanities and social sciences to a great extent.

\section{B. Science, improve the public scientific literacy with science and technology}

Science, in essence, is to use science and technology to improve personal quality, and enhance people's necessary ability to use them in solving practical problems and adjusting the interaction with environment. Science is about using science and technology to improve the public quality, while improve the quality of the public is a complicated systematic project. The popularization of science is not merely about knowledge, but it actually improves people's quality during the process. Science is to transfer knowledge, to develop intelligence, to renew the idea, and to cultivate spirit, which, after all, is to improve the comprehensive quality of people as its purpose expresses. Besides, scientific literacy is a concept advancing with the times, in want of timely adjustment with the development of science and technology and civilization. Gradually, the new technology in China and developed countries, and its expected social impact are becoming the focus with extensive attention. The public scientific literacy is an important concept full of vitality, and therefore, we should constantly concentrate on and research it. At the same time, strengthening education in an all-around way and popularizing science are undoubtedly basic approaches of improving and enhancing the public humanities and social science literacy.

\section{Forms of improving humanities and social science literacy}

Over the past 30 years, Jon miller, a professor at Michigan state university in the United States, has conducted an evaluation of the American public understanding of the science and technology level, and tested the relevant factors influencing people's attitude toward science. The pattern proposed in his "Public Understanding of Science (Public Understanding of Science, as the PUS)" has gradually become the basic standard which is set up by international community for the Public Scientific literacy. Its contents are mainly three aspects, namely, scientific knowledge, scientific methods, scientific attitude. Since the 1990 s, some scholars at abroad put forward the "KAP" pattern of public science literacy, in which the $\mathrm{K}$ (knowledge) refers to the public understanding of science knowledge, A (attitude) refers to the public attitude towards scientific knowledge and its social effects, and $\mathrm{P}$ (practice) refers to the means of scientific practice in public life. The "KAP" mode derives and amplifies "PUS" mode, with the ability to reflect the status of the humanities and social science literacy in the public.

Meanwhile, our country has made greater efforts to improve the public accomplishment of humanities and social science, and consequently, the level of public humanities and social science literacy in our country has improved impressively in recent years. However, the current level of Chinese public humanities and social science literacy still lags behind the requirements of modernization. Therefore, it is particularly important to explore the public mode of the construction of the humanities and social science literacy, to promote the all-round development of people and to accelerate the modernization in contemporary China. The humanities and social science mainly involve two levels, the knowledge about humanities and social science and humanistic spirit. With social focus on humanities, the forms of humanities and social science literacy are greatly diversified. Our educational system, scientific research institutions, and mass media function in strengthening the popularization of the knowledge about humanities and social science. However, this is only a foundation, it is crucial to convert the public acquaintance into consciousness, appearance into a daily behavior, and to cultivate their humanistic spirit fundamentally. Therefore, according to the present priority in China, the development of our public humanities and social science literacy is confronted with higher requirements of relying on science and education. Man is the soul of society, and social competition, by nature, is the competition for talents. In the fierce market competition, we should keep up with the rapid development of science and technology, and speed up the progress in science and technology, which raises a new and higher requirement for one's scientific and cultural quality, the ability to do scientific research and the level of professional skill, and sets a higher standard for the public literacy of humanities and social science to be included in pre-service training. Therefore, humanistic colleges and universities are important institutions that cultivate students with higher literacy of humanities and social science, higher scientific quality and professional skills, and that enhance a company's competitiveness and developmental potential. These institutions for higher learning play a crucial role in the education of social science and represent the public accomplishment in the forms of humanities and social science which would welcome a profound change, and serve as the important base for improving the public literacy of humanities and social science. 


\section{Analisis of the Strategies in Cultivating the HuMANITIES AND SOCIAL SCIENCE LITERACY}

As the common wealth of human beings, humanities and social science have strong historical inheritance. Creating social concept, enhancing the public literacy of the humanities and social science is a global major task in the business development of our party and nation. For a further transition of ideas, we should improve understanding, and fully realize the important practical significance of humanities and social science, and of actively and smoothly developing their promotion and popularization.

\section{A. To strengthen legal construction and the popularization of humanities and social science}

Since China's reform and opening up, our party and government have established the strategy of relying on science and education, held national conferences on science and technology and scientific work, and made many policies and regulations about the popularization of humanities and social science. However, because of the long-standing lack in appropriate laws and regulations, the publicity and popularization of philosophy and social science are limited to a certain degree, and the impact on the development of philosophy and social science makes it difficult to popularize social science and construct the working system, and to improve and implement long-term development plan. Therefore, we should popularize the laws and regulations concerning humanities and social science, as well as laws, humanities and social science as soon as possible.

\section{B. To increase the capital investment in the humanities and social science}

The popularization of humanities and social science is a public in society, which is impossible without some stable financial support. Thus, we should ensure that the popularization of humanities and social science works normally, increase the expenditure on the funds for social science, and encourage the personal support for philosophy and social science from all walks of life.

\section{To reward the good and punish the evil, self-discipline and heteronomy complement each other}

The improvement of public literacy of humanities and social science, on the one hand, relies on the enforcement of laws outside which pays attention to the hard constraints. On the other hand, it is accomplished through inner discipline that focuses on soft constraints. The spiritual state of the public would be lonely unless the two constraints are combined. To uphold the principle of governing the country according to law, we should find effective ways to improve the comprehensive quality of the public, to strengthen the supervision on every aspect of social life, and to reward good and punish evil. With self-discipline and heteronomy complementing each other, the words or deeds that are against the laws or virtues will be restricted and restrained. However, this project should also be accomplished consciously with self-discipline through improving the level of the public's civilization consciousness.

\section{To establish a mechanism for the humanities and social science research achievements}

Any kind of scientific research, only by playing its proper role can it has productive results. Although the cultivation of people's humanities and social science does not directly generate economic benefits, the level of its development and prosperity is an important embodiment and symbol of our cultural power as well as our nation's comprehensive accomplishment. Our excellent achievements in the humanities and social sciences propaganda show that we should dredge and continuously broaden the conversion of channels so that we can form an outstanding mechanism. We should pay attention to apply excellent results of humanities and social science cultivation to the decision-making of the party and the government. Meanwhile, it is prominent to solve the problem of reform, development and stability. We should also strengthen the countermeasure research, actively explore the solutions to difficulties meet in the economic and social development and serve for the decision-making department in our government. Furthermore, we should strive to gain research results which have both theoretical and academic values. The humanities and social science research aims at pacing up social development and promoting the public consciousness to improving their level of humanities and social sciences.

\section{E. Give full play to the mass media in the popularization of the humanities and social science}

The public access to knowledge can be varied. However, in China, people' $\mathrm{s}$ access to information is unitary---most people rely on television and newspapers to get information. Through these public facilities and venues, the ratio of giving a vivid form of education on science and technology is very low. Therefore, to improve the public accomplishment in the humanities and social sciences, mass media has its unshakable responsibility. Mass media is also the best way to improve the public accomplishment of humanities and social science. Mass media is born to be in front of the public, it should not be cynical and aims to spread scientific knowledge. For groups of less-educated people,we really have to enhance the role of mass media.

\section{F. Give full play to the role of the social science community,} to improve the public accomplishment in the humanities and social sciences and to play their role of promoting people's all-round development

Faced with the situation that public humanities and social science literacy is not high, the social science organizations at all levels need to make full use of their advantage in gathering social information and talents resources. They should also hold some public popularization and consulting activities in the field of social science at the grass-roots level. Various scientific research departments need to abandon their past idea of scientific research and popular science, they should work out scientific plans for holding promotion activities and use public language express their views based on the reality of discipline so as to guide the public to a world of humanities and social science. 
Therefore, valuing the moral consciousness of ecological civilization and developing the public accomplishment of humanities and social science will make the person and nature, man and society coexist harmoniously. Thus human beings fall into a virtuous cycle, where there are comprehensive development and sustainable prosperity on the basis of ethical culture. To make our children live better and our society continue to boom. We need to keep it in mind that we should not seek development at the cost of damaging the interests of our future generations. It is our responsibility to cherish every natural resource, to protect the ecological environment to improve the ecological environment and to leave a complete earth to our offspring. To form public humanities and social science, we must begin from constructing ecological civilization, improving citizens' public humanities and social science literacy, cultivating people's ecological ethic and arousing their self-consciousness.

\section{ACKNOWLEDGMENT}

In this paper, we'd likes to express our sincere appreciation for the Tianjin science and technology development strategy project (project number: 11 zlzlzf02700), Tianjin social sciences planning project (project number TJJX11-002), and Tianjin education plan key projects (project number CE2019) for their contribution to the research content.

\section{REFERENCES}

[1] Chengqing. Research on approaches and strategy to enhance public literacy, $20112^{\text {nd }}$ International Conference on Inf, ISBN978-93506854-9, 2011-05-30.

[2] Li Daguang.Significance of the investigation for public scientific literacy in China, Chinese public Science and Technology Network.

[3] An Zhifeng. Horizon of comprehensive development of ecological civilization. Master degree theses of master of Nanjing university of finance and economics, 2011 (9).

[4] Qu Haiyan. Ecological civilization horizon biddy university students to explore vocational education [J]. Journal of adult education, 2010/09 of the total 284 .

[5] Gao Jian. Ecological civilization horizon, the moral cultivation of college students' ecological education research, Nanjing forestry university, 2009 (6) 